\title{
The Cloud Paradigm: Geostable Molecules as Proxies for Surface Oxygenation
}

\author{
Roger E Summons*, Christian Hallmann \\ Department of Earth, Atmospheric, and Planetary Sciences, Massachusetts Institute of Technology, \\ Cambridge, MA 02139, USA \\ Jacob R Waldbauer
}

Joint Program in Chemical Oceanography, Massachusetts Institute of Technology and Woods Hole Oceanographic Institution, Cambridge, MA 02139, USA

\section{Laura Sherman}

Department of Earth, Atmospheric, and Planetary Sciences, Massachusetts Institute of Technology, Cambridge, MA 02139, USA; Department of Geological Sciences, University of Michigan, Ann Arbor, MI 48109, USA

Over the past fifty years, geoscientists have struggled to understand how and when earth's surface became habitable to complex, intelligent life. One of the prevailing scenarios, comprehensively articulated by Cloud, Holland and others, proposes an initially anoxic or very low $\mathrm{O}_{2}$ atmosphere. Although photosystem II appeared relatively early, there was an extended period of imbalance between sources and sinks of $\mathrm{O}_{2}$ through pervasive feedback between biosphere, atmosphere, hydrosphere and lithosphere.

*Corresponding author: rsummons@mit.edu

(C) China University of Geosciences and Springer-Verlag Berlin Heidelberg 2010

Manuscript received December 22, 2009.

Manuscript accepted February 10, 2010.
Ultimately, $\mathrm{O}_{2}$ accumulated in the atmosphere to near its present level at about $540 \mathrm{Ma}$. Life evolved concurrently. This talk examines new evidence for and against this idea based on the distributions and stable carbon isotopic values of molecular fossils that were extracted from well-preserved Late Archaean sediments. Samples were recovered as drill core from the Mount McRae Formation in the Mt. Bruce Supergroup, Pilbara craton and the Transvaal Supergroup of the Kaapvaal craton. The molecular fossils we identified comprise a diverse hydrocarbon assemblage including steroids that indicate that oxygen-dependent biosynthetic pathways were extant and carotenoid residues diagnostic for phototrophic sulfur bacteria. Both classes of compounds suggest that small amounts of $\mathrm{O}_{2}$ were available in the marine environment well before the Great Oxidation event. 